\title{
THE RELATIONSHIP BETWEEN SENSE OF COHERENCE AND GOAL SETTING
}

\author{
DJ NEL \\ ANNE CRAFFORD \\ GERT ROODT \\ Programme in Industrial Psychology \\ Department of Human Resource Management \\ Rand Afrikaans University
}

\begin{abstract}
The objective of this study was to investigate the relationship between the dimensions of Sense of Coherence and Goal Setting. A sample of 80 management consultants participated in the study. Confirmatory reliabilities of the dimensions used in the Goal Setting Questionnaire (independent variable) and Sense of Coherence 29 item Orientation to Life Questionnaire (dependent variable), ranged from 0,54 to 0,97. A canonical correlation of 0,569 $(\mathrm{DF}=39 ; \mathrm{p}=0,021)$ was obtained between the dimensions of these two questionnaires.
\end{abstract}

\section{OPSOMMING}

Die doelwit van hierdie studie was om die verband tussen die dimensies van Koherensiesin en Doelstelling vas te stel. 'n Steekproef van 80 bestuurskonsultante het aan die studie deelgeneem. Bevestigende betroubaarhede van die dimensies van die Doelstellingsvraelys (onafhanklike veranderlike) en die 29 item Lewensoriëntasievraelys (afhanklike veranderlike), het gewissel van 0,54 tot 0,97. ' $\mathrm{n}$ Kanoniese korrelasie van 0,569 $(\mathrm{gv}=39 ; \mathrm{p}=0,021)$ is verkry tussen die dimensies van die twee vraelyste.

For many years the medical and organisational worlds have focused on the negative physiological and psychological effects of stress by developing a well-founded pathogenic model. However, since the later half of the 20th century a salient shift in thinking has occurred. Research has evolved to focus on what Antonovsky (1987), has termed a 'salutogenic' model (from Latin, salus = health and genesis = origins). The basic premise of this shift is that where traditionally the focus has been on the origins of disease or illness and the treatment thereof, an emergent paradigm has shifted this focus to the origins of health, staying well and coping with the bombardment of daily stressors.

Salutogenesis is evidence in psychological literature of the effort to unravel what Antonovsky (1987) refers to as the 'mysteries of health'. Antonovsky uses the word 'mystery' in the sense that within the stressful and challenging environments we live and work in today, there are those who despite exposure to the same stressors as their peers, appear to more effectively resist the ill effects of stress. These individuals seem to have both consciously or unwittingly unravelled these mysteries of health. They have somehow applied in their lives what sustains wellness in the face of their peers, who time and again seem subjugated to overload and burnout (Antonovsky 1987, 1994).

The salutogenic shift is supported through the development of a number of well known theories such as Hardiness (Kobasa, 1979), Optimism (Scheier \& Carver, 1987) and Self-Efficacy (Bandura, 1977). However, Antonovsky as the protagonist of salutogenisis proposed that central to the latter, is the concept of Sense of Coherence. He refers to Sense of Coherence as an enduring and stable personality disposition and provides the following definition:

'Sense of coherence is a global orientation that expresses the extent to which one has a pervasive, enduring though dynamic feeling of confidence that (1) the stimuli deriving from one's internal and external environments in the course of living are structured, predictable and explicable; (2) the resources are available to meet the demands posed by the stimuli; and (3) these demands are challenges worthy of investment and engagement' (Antonovsky, 1987, p.19).

Requests for copies should be addressed to: A Crafford, Department of Human

Resource Management, RAU University, PO Box 524, Auckland Park, 2006
Central to this paper is the fact that research over the past 20 years has strongly substantiated Antonovsky's claims that individuals with a high Sense of Coherence are more resistant to the negative effects of stress and anxiety, which could otherwise result in a suppressed immunity system leaving an individual more prone to illness (Adams, Bezner, Drabbs, Zambarano \& Steinhardt, 2000; Carmel \& Bernstein, 1989; Hart, Hittner \& Paras, 1991; Kivimaki, Kalimo \& Toppinen, 1998; McSherry \& Holm, 1994; Strümpfer \& Wissing, 1998; Sullivan, 1995).

The above introduction thus highlights the importance of focussing on the positive aspects of health and brings to the fore, the question as to what organisations can do in support of promoting a healthy work environment in the face of ubiquitous stress. It is within this context that this research considers what relationship the use of goal setting may have on Sense of Coherence. The rationale being that goal setting is a straight forward and widely used motivational technique which has consistently shown a positive correlation with performance if certain related components of goal setting (referenced below), are included (Hinsz, 1995). If a positive and strong relationship is evident, goal setting may play a role in promoting Sense of Coherence in the workplace.

Background and theoretical considerations

Stress is a subtle foe and a topic of a great deal of interest to researchers especially in the wake of pervasive change in organisations (Worrall and Cooper, 1995). If one considers how the psychological contract has changed in the private sector from the encouragement of loyalty in exchange for a life long job, to one where experience, remuneration and change is the promise given in exchange for innovation, it is apparent that values have changed. With the increase in the number of e-businesses, dot.coms and large-scale software implementations undertaken by many staid organisations of the past, it is understandable that change is underwritten into every psychological contract formed today (Sauter, 2002).

Change is both a daunting and exciting possibility. It is exciting if one is able to comprehend the change, interpret it through a meaningful frame of reference and believe it is manageable, (i.e. if you have a high Sense of Coherence, Antonovsky, 1987); however, if one fears the change and feels ill prepared, it becomes a daunting concept. The result, 
although axiomatic, is that if change is perceived as a major stressor, the individual may struggle to process information required to cope with the change and be left in a state of distress. To compound the scenario, there is a substantial body of research, which posits links between stress and a host of diseases (Antonovsky 1979; 1987). To name but a few of the major correlations, stress has been shown to have strong links with the spread of cancer, vulnerability to viral infections, diabetes, and coronary heart disease (Goleman, 1995; Strümpfer, 1986; Sullivan, 1995).

In addition, the field of Psycho-Neuro-Immunology (PNI) substantiates these claims by suggesting that particular psychological predispositions (such as optimism), cause complex hormonal reactions in our bodies, that result in either stimulating or suppressing our immunity systems (KiecoltGlaser, McGuire, Robles \& Glaser, 2001). In a follow-up study, Kiecolt-Glaser et al. (2002) cite research, which proposes that stress and negative moods result in the secretion of proinflammatory cytokines (protein substances which regulate the immune response to injury and infection). In particular, IL6 (one of several such cytokines) plays a central role in the production of C-Reactive Protein (CRP) and the combination of these two is 2,6 times more likely to predict myocardial infarction than elevated blood pressure or cholesterol (KiecoltGlaser et al., 2002). This is alarming evidence to further promote focus on the salutogenic over a predominantly pathogenic historical focus.

The collective effect of this could be disastrous for an organisation. Sullivan (1995) estimated that $70 \%$ of all absenteeism is related to stress induced illness. This figure is substantiated by Carolyn (2001) who cites research by the Industrial Society, a London based research and advocacy organisation, that nearly $80 \%$ of all human resource specialists surveyed cited stress as the main cause of absenteeism. An alarming thought when one calculates that the absenteeism cost the UK in excess of $£ 10.7$ billion in 2000 (Carolyn, 2001).

Further research identifies high stress levels as being associated with reduced performance and productivity, decreased job satisfaction, a decline in organisational commitment and loyalty and an increase in accidents, medical costs and turnover (Hobson, Delunas \& Dawn, 2001; Sullivan, 1995). Cascio (1989) adds to this list the indirect costs of low morale, motivation, communication breakdowns and a negative affect on the quality of work relations. The National Institute for Occupational Safety and Health in the US has conducted research into stress at work and they add to the above by citing $40 \%$ of job turnover in the US is due to stress, a further $60-80 \%$ of accidents on the job are stress related (NIOSH, 2002).

The prevalence, ill effects and difficult treatment of stress, unless one is aware of and able to deal with the specific origin thereof, generates further credence for the organisation to focus on techniques and an environment, which will foster concepts such as Sense of Coherence. Such a focus will equip the individual to withstand varied stressors multiple life situations often bring (Antonovsky, 1994).

\section{Sense of Coherence}

As an individual progresses through life, exposure to certain challenges and stressors will either result in the individual being able to handle the situation or being overcome by the challenge Antonovsky (1979). The result of emerging triumphant through the challenge is the formation of what Antonovsky refers to as Generalised Resistance Resources (GRR's). Antonovsky described GRR's as 'making sense out of the countless stressors with which we are constantly bombarded' (1987, p. xiii). In essence these GRR's are learned experiences or ways of dealing with stress. They are more than just a coping mechanism or strategy, but a belief system developed on the basis of stimulus - response, they are essential learnt behaviour styles. Through repeated experiences of such sense making (being able to apply the GRR's in a challenging time of life), a person develops over time, a strong Sense of Coherence (Strümpfer, 1990).

Examples of GRR's can be seen in being able to rely on a parent in times of stress, see an individual diffuse tension through conversation, or even taking a pill to deal with a symptom of illness. Antonovsky (1987) described a range of GRR's, namely:

- Physical and biochemical, like immunosuppressors and stimulators;

- Artefactual material GRR's, particularly wealth, that can buy for example, food and clothing or a safe abortion for an unwanted pregnancy, but also power, status and services;

- Cognitive GRR's particularly knowledge-intelligence, contingent on education, which includes skills, but also knowledge, for example about avoiding HIV or carcigens;

- The emotional GRR of ego identity;

- Coping strategies, as overall plans for overcoming stressors;

- Interpersonal-relational GRR's, such as social support and commitment; and

- Lastly, the macrosociocultural GRR's of ready answers provided by one's cultural and social structure, which includes religion.

Through a process of structured interviews with individuals who had suffered major life difficulties, including concentration camps, years of economic deprivation and loss of loved ones, Antonovsky (1987) noticed patterns emerge in terms of those individuals who were more able to resist the ill effects of stress through applying these GRR's. He has consolidated these patterns into three major themes and has operationalised them as the following (Flannery \& Flannery, 1990; McSherry \& Holm, 1994):

- Comprehensibility, the certainty by which one can anticipate possible events and the degree that perceived stimuli make cognitive sense;

- Manageability, the degree to which one believes that one has available resources to deal with a challenge and that the deployment of these resources (either ones own or those of a legitimate other) will address the challenge and;

- Meaning, the feeling that life makes sense and that it is worthy of investment commitment and engagement of these resources.

The above three themes comprise the three components of Antonovsky's Sense of Coherence (1987). The advantages of a strong Sense of Coherence are salient in that an individual will interpret their world with meaning, viewing it as comprehensible and manageable. Such an orientation positions the individual to optimally handle stress and even turn it into something positive (Antonovsky, 1994).

Strümpfer (1990, p.120) highlighted the following characteristics of a person with a high Sense of Coherence in an organisational context, in that this individual will:

- Make cognitive sense of their workplace, perceiving its stimulation as clear, ordered, structured, consistent and predictable information;

- Perceive their work as consisting of experiences that are bearable, with which they can cope and as challenges they can meet by availing themselves of personal resources or those under the control of legitimate others;

- Make emotional and motivational sense of work demands as welcome challenges, worthy of engaging and investing energies in.

On the other end of the scale, Strümpfer (1990) provides a succinct summary of a person with a low Sense of Coherence. He asserts that these individuals would suffer an information

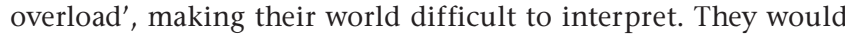


feel the victim of circumstances beyond their control and thus burdened by having to accept the negative outcomes thereof. The consequences of the above would result in potential immobilisation and the inability to excel in stressful situations.

Considering that one of the primary goals of Industrial Psychology is to optimise work behaviour, the question of how malleable the concept of Sense of Coherence is comes to the fore. Antonovsky (1987) highlighted the fact that certain environments or significant life events can influence the strength of a person's Sense of Coherence, however, he cautioned that the formation of the construct over ones life will make it difficult to greatly or permanently change one's overall Sense of Coherence.

It is the position of this paper that although this construct may already be formed within an individual having started their career, this does not negate the opportunity for the individual to use the principles embodied in the construct, to consciously and actively manage daily stressors. Furthermore, organisational support for the principles of Sense of Coherence, could create at the least a temporary Sense of Coherence at a highly stressful time. Hence the organisation could manage the environment of the individual and consequently, even temporarily, create a buffer against stress.

\section{Goal setting theory}

Goal Setting is a motivational technique used by both individuals and organisations to improve performance (Hinsz, 1995). The theory of goal setting was introduced by Locke in 1968 and has enjoyed a substantial review in the psychological arena over the past three decades (Tubbs, 1986). Through a meta analysis of the research, Locke, Shaw, Saari and Latham (1981) attest to the high reliability of goal setting as a technique to increase performance, in that over $90 \%$ of the research conducted concludes that there is a significant, positive and linear relationship between goal setting and performance.

In summary of this research over the past 30 years, it is evident that specific and challenging goals will lead to higher performance when compared with easy or 'do your best' goals (Kalnbach \& Hinsz, 1999). However, one also needs to take into account the general mediating effects of goal commitment on assigned and self set goals, in that self set goals usually result in more commitment, influencing performance (Hollenbeck \& Klein, 1987). The specific mediating effects of self-efficacy, in the case of assigned goals also deserves credence in that individuals with a higher sense of self-efficacy will generally outperform peers with a lower self-efficacy in the context of assigned goals (Kalnbach \& Hinsz, 1999). Hollenbeck and Klein (1987) propose that various personal and situational factors, for example, a high need for achievement and a conducive social influence, will impact the attractiveness and expectancy of goal attainment. The interactive combination of these two factors (attractiveness and expectancy) forms the basis of goal commitment (Hollenbeck \& Klein, 1987). Constructive feedback, support and the prospect of reward will further improve performance and could also increase commitment to the attainment of the goal (Hollenbeck \& Klein 1987; Locke et al., 1981).

Within the context of the above, the use of goal setting will act as a motivational tool by directing attention, mobilising effort, increasing persistence and motivating the ability to develop the most applicable strategy in the face of a variety of pressures (Locke et al., 1981; Terborg, 1976).

In support of the above, most goal setting research has employed experimental design to assess the benefits of setting goals (Tubbs, 1986). Individuals were assigned a task and using a control and experimental group, researchers identified the differences in performance based on the use or absence of goal setting. The research has yielded highly consistent results as the experimental designs, have largely mediated against the effects of extraneous variables to arrive at the theory presented above (Tubbs, 1986).

The emphasis on assigning goals to groups of individuals (as in the case of research employing the use of experimental designs) has, however, left the development of a questionnaire to assess the effective use of goal setting, unaddressed until the 1980's (Locke and Latham, 1984). In 1984 Locke and Latham proposed a goal setting questionnaire in an attempt to measure the perceptions of goal setting programmes and specifically the core goal attributes of specificity and difficulty, as well as related attributes and moderating variables that may exist in organisational settings. Locke and Latham (1984) were interested as to whether or not a general questionnaire could capture all the principles of goal setting and based on this, assess and advise organisations of which principles of goal setting they would need to focus on. However, it was only seven years later that the specific psychometric properties of this questionnaire were validated (see Table 2 below) (Lee, Bobko, Early, \& Locke, 1991). The study conducted by Lee et al. (1991) revealed 10 second order factors which emerged, these are discussed below.

1. Supervisor support/participation related to the willingness of the supervisor to allow the individuals to be involved with goal setting and strategies.

2. Goal stress, referred to the excess difficulty and stressfulness of the goals and the respondent's failure to attain their goals.

3. Goal efficacy involved the existence of action plans, job training, feedback and the enjoyment of reaching one's goals.

4. Goal rationale related to the clarity of the performance - goal relationship and overall rationale underlying the goals.

5. Use of goal setting in performance appraisal dealt with the specific process involved in the appraisal process.

6. Tangible rewards represented the probability that successful attainment of the goal would lead to job security, an increase or promotion.

7. Goal conflict, referred to a number of different conflicts in attaining the goal, such as inter-role conflict, ambiguous messages from supervisors, too many goals and conflict with personal values.

8. Organisational facilitation of goal achievement includes reference to the organisational policies and procedures as well as the supervisory efforts in supporting attainment of the goal.

9. Dysfunctional effects of goals, was the converse in the sense that the organisation or supervisor were non supportive of goals and cases where goals resulted in punitive action.

10.Goal clarity related to how clear goals are and the resulting ability to prioritise them.

As expected, the above 10 dimensions are reflective of the principles of goal setting discussed in the review of literature above. The only omissions and unfortunately rather conspicuous at first glance are the absence of factors specificity and difficulty, most certainly the two most prominent of the factors emerging over the past three decades. Locke and Latham (1984) originally intended for these dimensions, however, questions related to these two components, were seen to load on goal rationale, clarity and organisational facilitation of goal achievement, respectively. Based on the lack of distinct difference in terms of these two factors emerging in their own right, with permission of Edwin Locke, seven questions were added to assess three separate and additional factors referred to in the literature yet not salient in the priori structure of the questionnaire. These additional dimensions are:

- Goal Specificity involving being able to 'break goals down', identify components thereof and reduce the goal to writing.

- Goal Difficulty referring to the amount of effort and persistence involved in achieving a goal. 
- Goal Commitment, the amount of motivation related to achieving the goal and; the degree to which the individual sets their own goals once a 'higher' goal has been assigned to them.

It is the purpose of this research to consider how effective the use of only questionnaires in the form of a survey design representing both constructs (Sense of Coherence and goal setting) will be, as opposed to using experimental designs mentioned above. Based on the effectiveness of the results, a survey design affords the opportunity of expedient assessment of situation without experimental intervention.

\section{The relationship between Sense of Coherence and goal setting \\ It is important to note that in a review of several research databases, as well as discussions with leading researchers in this domain, no study to assess the correlation between Sense of Coherence and goal setting, using the Goal Setting Questionnaire developed by Locke and Latham (1984), was found. Hence this work was exploratory in nature and there were no studies to use as reference when formulating the objectives of the study and consequent hypothesis.}

However, based on the review of both constructs presented above, this research explores the premise, that goal setting as a widely used and accepted technique is a simple but highly effective method (if correctly applied), for organisations to create an environment which may promote the necessary components of Sense of Coherence.

Considering the components of Sense of Coherence and the factors emerging in the Locke and Latham (1984) Goal Setting Questionnaire, the following relationships between the two constructs and their dimensions were assumed.

A relationship between Meaning within Sense of Coherence and, Tangible Rewards, Goal Rationale as well as Goal Commitment, was assumed on the grounds that if an individual sees value in attaining a goal, understands the 'why' of the goal, these should precede a sense of commitment (Hollenbeck and Klein, 1987), these factors collectively making the goal 'worthy of investment' or have Meaning (Antonovsky, 1987).

In addition Manageability within Sense of Coherence could be enhanced if Supervisory Support is given in attainment of the goal, the individual has a sense of Goal Efficacy and there is Organisational Facilitation of Goal Achievement. This relationship is assumed on the grounds of creating an environment in which the individual believes they have the necessary resources or support at their disposal to deal with the challenges or stressors (Antonovsky, 1987).

Finally, the relationship with Comprehensibility within Sense of Coherence and goal setting would seem logically supported through Goal Clarity and Goal Specificity. This on the basis of the fact that the individual with a clear understanding of the specifics related to a challenge will feel more equipped to deal with the challenge (Antonovsky, 1987).

\section{METHOD}

Objectives of the study

The principal objective of the study was to determine the relationship between dimensions of the Goal Setting Questionnaire (GSQ) as validated by Lee et al. (1991) and the 29 item Orientation to Life Questionnaire (OLQ) that Antonovsky (1987) developed to measure Sense of Coherence. Corollaries were to examine the stepwise regression of correlated dimensions of the GSQ on the 29 item OLQ as well as the emergent reliabilities of each dimension. In addition the reliabilities of the added questions introduced in respect of the additional three proposed goal setting dimensions, were assessed.

In the light of the principal objective of the study, the following hypothesis was formulated:

\section{Hypothesis 1}

There is a statistically significant canonical correlation between the Sense of Coherence dimensions of Antonovsky's (1987) 29 item OLQ (dependent variables) and certain dimensions of the GSQ (independent variables) as presented by Lee et al. (1991).

\section{Research design}

A field survey design was used to achieve the research objective (Shaughnessy \& Zechmeister, 1997). The study is thus quantitative and ex post facto in nature.

\section{Participants}

Eighty management consultants from the South African office of one of the largest management consulting firms, globally, participated in the study. This sample of participants was one of convenience, from a population of approximately 750 consultants, due to the difficulty of accessing the participants to administer the questionnaires. Although the sample represents only $12 \%$ of the population, other such surveys have yielded a similar percentage of responses, due to the voluntary nature of surveys and the stringent work deadlines constantly imposed on these employees. The biographical data available is presented in Table 1 below and shows that there were an even proportion of male and female participants, most were single, more than $70 \%$ possessed a university degree and the average age was 32 .

TABLE 1

BIOgRAPHICAL DATA OF SAMPLE

\begin{tabular}{lcc}
\hline \multicolumn{2}{c}{ Gender } \\
\hline & Count & $\%$ \\
Male & 39 & $49 \%$ \\
Female & 41 & $51 \%$ \\
Total Gender & 80 & $100 \%$ \\
\hline & Marital Status \\
& \\
& Count & $\%$ \\
Married & 23 & $29.1 \%$ \\
Single & 34 & $41.8 \%$ \\
Divorced & 1 & $1.3 \%$ \\
Not Indicated & 22 & $27.8 \%$ \\
Total Marital Status & 80 & $100.0 \%$ \\
\hline
\end{tabular}

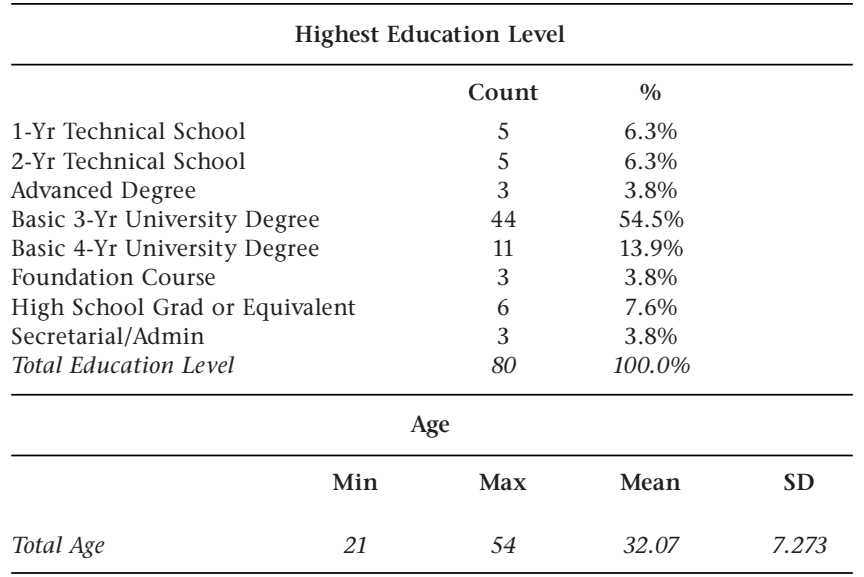

Measuring instruments

Sense of Coherence

Antonovsky's 29 item OLQ, is a seven point Likert type scale developed in 1983 (Antonovsky, 1987) and is a normative 
measure of an individual's global orientation to coping. Through three subscales, the OLQ measures all three dimensions of Sense of Coherence, namely Meaning, Manageability and Comprehensibility (as defined above).

Antonovsky (1987) provided an evaluation of studies conducted using the 29 item OLQ from 1983 to 1987 with resulting Cronbach alpha coefficients ranging from 0,84 to 0,93 indicating a respectable degree of internal consistency. Strümpfer and Wissing (1998) collated all studies in South Africa utilising the scale and from a total of 47 studies, found a mean Cronbach alpha of 0,87. A further advantage of this research by Strümpfer and Wissing (1998), was the identification of a mean score for the 29 item OLQ for South Africans, of 137.

Goal Setting Questionnaire (GSQ)

The GSQ is a 53 item questionnaire, utilising a five point Likert type scale where individuals indicate their agreement or disagreement with questions (Lee et al., 1991).

Lee et al. (1991) identified 10 higher order factors with reliability coefficients ranging from 0,63 to 0,88 , shown in Table 2 below.

TABle 2

A PRIORI STRUCtURE OF THE GOAL SETTING QUESTIONNAIRE

\begin{tabular}{|c|c|c|c|c|c|}
\hline No. & Factor & Items & Mean & S.D. & Alpha \\
\hline 1 & Supervisor support/participation & 3 & 3,8 & 0,98 & 0,82 \\
\hline 2 & Goal stress & 3 & 2,3 & 0,75 & 0,68 \\
\hline 3 & Goal efficacy & 4 & 4,0 & 0,68 & 0,68 \\
\hline 4 & Goal rationale & 4 & 3,4 & 0,91 & 0,78 \\
\hline 5 & $\begin{array}{l}\text { Use of goal setting in } \\
\text { performance appraisal }\end{array}$ & 9 & 3,5 & 0,83 & 0,88 \\
\hline 6 & Tangible rewards & 4 & 3,2 & 0,94 & 0,74 \\
\hline 7 & Goal conflict & 8 & 2,1 & 0,69 & 0,85 \\
\hline 8 & $\begin{array}{l}\text { Organisational facilitation of } \\
\text { goal achievement }\end{array}$ & 5 & 3,3 & 0,71 & 0,63 \\
\hline 9 & Dysfunctional effects of goals & 7 & 1,7 & 0,70 & 0,85 \\
\hline 10 & Goal clarity & 4 & 4,0 & 0,69 & 0,67 \\
\hline
\end{tabular}

\section{Research procedure}

Due to the diverse and geographically dispersed projects employees of the firm work on, it was necessary to employ a variety of methods to obtain responses. A presentation on the research and a request to participate in the study was made at several workshops and at one large conference (involving approximately 300 ), individuals were also approached via their project managers. A final attempt to increase the numbers was also made by e-mail, however, this did not prove successful. Individuals participating, completed the questionnaires in their own time and returned them to the author by a designated date.

\section{RESULTS}

The resulting confirmatory factor analysis reliabilities are presented in Table 3. It is important to note that exploratory factor analysis was not possible due to the small sample size, however, the reliabilities of both the 29 item OLQ and GSQ already established were considered satisfactory, especially in conjunction with the confirmatory reliability analysis discussed below.
TABLE 3

RELIABILITIES OF THE DIMENSIONS OF THE 29 ITEM OLQ AND THE GSQ DIMENSIONS (CRONBACH ALPHA)

\begin{tabular}{llc}
\hline & & Sense of Coherence \\
No. & Dimension & Reliability \\
\hline 1 & Meaning & 0,804 \\
2 & Comprehension & 0,785 \\
3 & Manageability & 0,808 \\
\hline & & \\
& & Reliability \\
No. & Dimension & 0,880 \\
\hline 1 & Supervisor support/participation & 0,701 \\
2 & Goal Stress & 0,630 \\
3 & Goal Efficacy & 0,814 \\
4 & Goal Rationale & 0,941 \\
5 & Use Of Goal Setting In Performance Appraisal & 0,810 \\
6 & Tangible Rewards & 0,796 \\
7 & Goal Conflict & 0,799 \\
8 & Organisational Facilitation Of Goal Achievement & 0,873 \\
9 & Dysfunctional Effects Of Goals & 0,739 \\
10 & Goal Clarity & 0,637 \\
11 & Goal Specificity & 0,754 \\
12 & Goal Difficulty & 0,545 \\
13 & Goal Commitment & \\
\hline
\end{tabular}

All three dimensions of the Sense of Coherence scale reflect high internal consistencies with reliabilities ranging from 0,785 to 0,807 , thus validating the reliability findings presented by Antonovsky above.

In terms of goal setting, there is a greater range in the reliabilities for the goal setting dimensions ranging from 0,545 to 0,942 . In comparison with the original reliabilities found by Lee et al. (1991), the findings of this research are very similar bar the increased reliability of Organisational Facilitation of Achievement in this research $\left(r_{x x}=0,799\right)$ as opposed to Lee et al. (1991) of $r_{x x}=0,63$. In addition, all obtained reliabilities in this study remain satisfactory in comparison with the reliabilities obtained by Lee et al., except possibly Goal Efficacy which produced a reliability of 0,63 in this study, in comparison with 0,68 obtained by Lee et al.

Of particular interest are the reliabilities of the additional dimensions added to the original questionnaire. Of these Goal Difficulty showed the highest internal consistency with a $r_{x x}=0,754$, followed by Goal Specificity with $a r_{x x}=0,636$, however, Goal Commitment yielded a reliability of only 0,545 . The lower reliability of this dimension implies it should be viewed with circumspection when interpreting the results of the stepwise regression in Table 9 below.

The dimensions of the 29 item OLQ and the GSQ, were correlated using Pearson's Product Moment Correlation, the results appear in Table 4.

Table 4 shows a number of statistically significant correlations at the 0,01 and 0,05 level for a 2 tailed test. Of particular interest are the correlations that exist between the 29 item OLQ dimensions and the GSQ dimensions. The highest correlations were between the goal setting dimensions: Organisational Facilitation of Goal Achievement, Dysfunctional Effects of Goals, Goal Clarity and Goal Specificity and the Sense of Coherence dimensions of Meaning and Manageability. In addition, the Sense of Coherence dimension, Meaning, also showed a strong positive correlation with goal setting dimensions: Goal Conflict, Goal Efficacy, Goal Rationale and Supervision Support in Goal Setting.

The canonical correlations between the independent variables (IV's) and dependent variables (DV's) were calculated. To test 
TABLE 4

INTERCORRELATION MATRIX OF THE COMPONENTS OF THE 29 ITEM OLQ AND THE GSQ

\begin{tabular}{|c|c|c|c|c|c|c|c|c|c|c|c|c|c|c|c|c|}
\hline & Mean & Comp & Mgbility & $\begin{array}{l}\text { Suprvsion } \\
\text { Support/ } \\
\text { Participat }\end{array}$ & $\begin{array}{l}\text { Goal } \\
\text { Stress }\end{array}$ & $\begin{array}{c}\text { Goal } \\
\text { Efficacy }\end{array}$ & $\begin{array}{c}\text { Goal } \\
\text { Rat }\end{array}$ & $\begin{array}{l}\text { GS in } \\
\text { Perf App }\end{array}$ & $\begin{array}{l}\text { Tangible } \\
\text { Rewards }\end{array}$ & $\begin{array}{c}\text { Goal } \\
\text { Conflict }\end{array}$ & $\begin{array}{c}\text { Org Fac } \\
\text { of Goal } \\
\text { Ach }\end{array}$ & $\begin{array}{l}\text { Dysfunct } \\
\text { effects of } \\
\text { goals }\end{array}$ & $\begin{array}{l}\text { Goal } \\
\text { Clarity }\end{array}$ & $\begin{array}{l}\text { Goal } \\
\text { Spec }\end{array}$ & $\begin{array}{l}\text { Goal } \\
\text { Diff }\end{array}$ & $\begin{array}{l}\text { Goal } \\
\text { Comm }\end{array}$ \\
\hline Meaning & 1,000 & $0,563^{* *}$ & $0,637^{* *}$ & 0,391 ** & $0,307^{* *}$ & $0,432^{* *}$ & 0,421 ** & $0,420^{* *}$ & $0,229^{*}$ & $0,470^{* *}$ & $0,424^{* *}$ & $0,421^{* *}$ & $0,426^{* *}$ & $0,470^{* *}$ & 0,093 & 0,374 * * \\
\hline Comprehension & $0,563^{* *}$ & 1,000 & $0,741^{* *}$ & $0,299 * *$ & $0,270^{* *}$ & $0,342^{* *}$ & $0,310^{* *}$ & $0,263^{* *}$ & 0,103 & $0,372^{* *}$ & $0,307^{* *}$ & $0,375^{* *}$ & $0,385^{* *}$ & $0,386^{* *}$ & $-0,090$ & 0,062 \\
\hline Manageability & $0,637^{* *}$ & $0,741 * *$ & 1,000 & $0,257^{*}$ & $0,358^{*}$ & $0,377^{*}$ & $0,350^{* *}$ & $0,393^{* *}$ & $0,251^{*}$ & $0,371^{* *}$ & 0,429 ** & $0,488^{* *}$ & $0,448^{* *}$ & $0,427^{*}$ & 0,013 & 0,191 \\
\hline $\begin{array}{l}\text { Supervision Support/ } \\
\text { parti }\end{array}$ & 0,391 * * & $0,299^{* *}$ & $0,257^{*}$ & 1,000 & 0,212 & $0,519^{* *}$ & $0,803^{* *}$ & $0,553^{* *}$ & $0,227^{* *}$ & $0,727^{* *}$ & $0,526^{* *}$ & $0,759^{* *}$ & $0,531^{* *}$ & $0,433^{* *}$ & $-0,089$ & 0,063 \\
\hline Goal Stress & $0,307^{* *}$ & $0,270^{* *}$ & $0,358^{*}$ & 0,212 & 1,000 & 0,428 ** & $0,348^{* *}$ & $0,422^{* *}$ & 0,137 & $0,419^{* *}$ & $0,452^{\text {** }}$ & $0,327^{* *}$ & $0,406^{* *}$ & $0,431^{* *}$ & $-0,28$ & $0,220^{*}$ \\
\hline Goal Efficacy & $0,432^{* *}$ & $0,342^{* *}$ & $0,377^{*}$ & $0,519^{* *}$ & 0,428 ** & 1,000 & $0,606^{* *}$ & 0,381 ** & $0,252^{*}$ & $0,542^{* *}$ & $0,552^{\text {** }}$ & $0,574^{* *}$ & $0,729^{* *}$ & $0,552^{* *}$ & $0,223^{*}$ & $0,420^{* *}$ \\
\hline Goal Rationale & $0,421^{* *}$ & $0,310^{* *}$ & $0,350^{* *}$ & $0,803^{* *}$ & $0,348^{* *}$ & $0,606^{* *}$ & 1,000 & $0,679^{* *}$ & $0,232^{*}$ & $0,696^{* *}$ & $0,703^{* *}$ & $0,713^{* *}$ & $0,659^{* *}$ & $0,558^{* *}$ & 0,84 & 0,165 \\
\hline $\begin{array}{l}\text { GS in Performance } \\
\text { Appraisal }\end{array}$ & $0,420^{* *}$ & $0,263^{* *}$ & $0,393^{* *}$ & $0,553^{* *}$ & $0,422^{* *}$ & $0,381^{* *}$ & 0,679 * * & 1,000 & 0,183 & $0,606^{* *}$ & $0,610^{* *}$ & $0,672^{* *}$ & $0,446^{* *}$ & $0,459^{* *}$ & 0,065 & 0,107 \\
\hline Tangible Rewards & $0,229^{*}$ & 0,103 & $0,251^{*}$ & $0,227^{* *}$ & 0,137 & $0,252^{*}$ & $0,232^{*}$ & 0,183 & 1,000 & $0,229^{*}$ & $0,286^{* *}$ & $0,303^{* *}$ & 0,126 & 0,084 & $-0,038$ & 0,207 \\
\hline Goal Conflict & $0,470^{* *}$ & $0,372^{* *}$ & $0,371^{* *}$ & $0,727^{* *}$ & $0,419^{* *}$ & $0,542^{* *}$ & $0,696^{* *}$ & $0,606^{* *}$ & $0,229^{*}$ & 1,000 & $0,516^{* *}$ & $0,754^{* *}$ & $0,505^{* *}$ & $0,484^{* *}$ & $-0,59$ & 0,182 \\
\hline $\begin{array}{l}\text { Org Facilitation of } \\
\text { Goal Achieve }\end{array}$ & $0,424^{* *}$ & $0,307^{* *}$ & 0,429 ** & $0,526^{* *}$ & $0,452^{* *}$ & $0,552^{* *}$ & $0,703^{* *}$ & $0,610^{* *}$ & $0,286^{* *}$ & $0,516^{* *}$ & 1,000 & $0,618^{* *}$ & $0,686^{* *}$ & 0,462 ** & $-0,060$ & 0,136 \\
\hline $\begin{array}{l}\text { Dysfunctional effects } \\
\text { of goals }\end{array}$ & $0,421^{* *}$ & $0,375^{* *}$ & $0,488^{* *}$ & $0,759^{* *}$ & $0,327^{* *}$ & $0,574^{* *}$ & $0,713^{* *}$ & 0,672 ** & $0,303^{* *}$ & $0,754^{* *}$ & $0,618^{* *}$ & 1,000 & $0,580^{* *}$ & $0,402^{* *}$ & $-0,111$ & 0,039 \\
\hline Goal Clarity & $0,426^{* *}$ & $0,385^{* *}$ & $0,448^{* *}$ & $0,531^{* *}$ & $0,406^{* *}$ & $0,729^{* *}$ & $0,659^{* *}$ & $0,446^{* *}$ & 0,126 & $0,505^{* *}$ & $0,686^{* *}$ & $0,580^{* *}$ & 1,000 & $0,690^{* *}$ & 0,175 & $0,300^{* *}$ \\
\hline Goal Specificity & $0,470^{* *}$ & $0,386^{* *}$ & $0,427^{*}$ & $0,433^{* *}$ & $0,431^{* *}$ & $0,552^{* *}$ & $0,558^{* *}$ & $0,459^{* *}$ & 0,084 & $0,484^{* *}$ & $0,462^{\text {** }}$ & $0,402^{* *}$ & $0,690^{* *}$ & 1,000 & $0,325^{* *}$ & 0,495 * * \\
\hline Goal Difficulty & 0,093 & 0,090 & 0,013 & $-0,089$ & $-0,28$ & $0,223 *$ & 0,840 & 0,065 & $-0,038$ & $-0,59$ & $-0,060$ & $-0,111$ & 0,175 & $0,325^{* *}$ & 1,000 & $0,589^{* *}$ \\
\hline Goal Commitment & $0,374 * *$ & 0,062 & 0,191 & 0,063 & $0,220^{*}$ & 0,420 ** & 0,165 & 0,107 & 0,207 & 0,182 & 0,136 & 0,039 & $0,300^{* *}$ & $0,495^{* *}$ & 0,589 ** & 1,000 \\
\hline
\end{tabular}

The overall correlation between all Sense of Coherence dimensions and all Goal Setting dimensions was 0.532 **

** Denotes statistically significant at the 0.01 level (2-tailed)

* Denotes statistically significant at 0.05 level (2-tailed)

the statistical significance of the obtained canonical correlations, Bartlett's chi-square test was used. The results are given in Table 5 .

TABLE 5

\section{CANONical CORRELATIONS}

\begin{tabular}{l|ccccccc}
\hline $\begin{array}{l}\text { Root } \\
\text { Removed }\end{array}$ & \multicolumn{5}{|c}{ Chi-Square tests with successive roosts removed } \\
\hline & Canonical R & Canonical R & Chi-sqr. & DF & p & $\begin{array}{c}\text { Lambda } \\
\text { Prime }\end{array}$ \\
\hline 0 & 0,569 & 0,323 & 58,934 & 39 & 0,021 & 0,453 \\
1 & 0,505 & 0,255 & 29,762 & 24 & 0,192 & 0,670 \\
2 & 0,316 & 0,099 & 7,817 & 11 & 0,730 & 0,900 \\
\hline
\end{tabular}

From Table 5 it is evident that only one of the canonical correlations is statistically significant $\left[\chi^{2}(39)=58,934 ; p=\right.$ $0,021]$. The obtained canonical correlation is 0,569 .

The canonical correlation analysis is given in Table 6 .

Table 6 shows that the following dimensions of the GSQ (IV's) have moderate to high loadings on the first variate: Goal Setting in Performance Appraisal, Organisational Facilitation of Goal Achievement, Dysfunctional Effects of Goals, Goal Clarity. Furthermore, all three dimensions of the 29 item OLQ; Meaning, Comprehension and Manageability (DV's) have high loadings on the same variate. The highest loading on the independent side of the variate is on Dysfunctional Effects of Goals $(0,715)$, and the highest loading on the dependent side is on Manageability $(0,988)$. Additional loadings on the independent variable side comparably high were; Organisational Facilitation of Goal Achievement $(0,616)$ and Goal Clarity $(0,601)$.
TABLE 6

Canonical CORRELATIONS OF GSQ Dimensions (IV's) WITH 29 ITEM OLQ DIMENSIONS (DV'S)

\author{
Canonical Correlations Correlations of Original \\ Measures with Canonical Variates
}

Variate 1 Variate 2 Variate 3

\begin{tabular}{|c|c|c|c|c|c|}
\hline & Independent Variables & & & & \\
\hline 1 & $\begin{array}{l}\text { Supervisor support/ } \\
\text { participation }\end{array}$ & 0,315 & 0,553 & 0,062 & \\
\hline 2 & Goal stress & 0,424 & 0,294 & 0,054 & \\
\hline 3 & Goal efficacy & 0,462 & 0,368 & 0,018 & \\
\hline 4 & Goal rationale & 0,486 & 0,469 & $-0,111$ & \\
\hline 5 & $\begin{array}{l}\text { Use of goal setting in } \\
\text { performance appraisal }\end{array}$ & 0,532 & 0,363 & $-0,157$ & \\
\hline 6 & Tangible rewards & 0,369 & 0,017 & $-0,353$ & \\
\hline 7 & Goal conflict & 0,449 & 0,685 & 0,059 & \\
\hline 8 & $\begin{array}{l}\text { Organisational facilitation } \\
\text { of goal achievement }\end{array}$ & 0,616 & 0,300 & $-0,228$ & \\
\hline 9 & $\begin{array}{l}\text { Dysfunctional effects } \\
\text { of goals }\end{array}$ & 0,715 & 0,264 & $-0,048$ & \\
\hline 10 & Goal Clarity & 0,601 & 0,308 & 0,068 & \\
\hline 11 & Goal Specificity & 0,485 & 0,576 & 0,070 & \\
\hline 12 & Goal Difficulty & $-0,068$ & 0,145 & $-0,248$ & \\
\hline \multirow[t]{4}{*}{13} & Goal Commitment & 0,130 & 0,459 & $-0,471$ & \\
\hline & $\begin{array}{l}\text { Average } \% \text { variance } \\
\text { accounted for }\end{array}$ & $21,98 \%$ & $16,69 \%$ & $4,00 \%$ & Total: $42,67 \%$ \\
\hline & Average $\%$ redundancy & $7,12 \%$ & $4,26 \%$ & $0,39 \%$ & Total: $11,77 \%$ \\
\hline & Dependent Variables & & & & \\
\hline 1 & Meaning & 0,531 & 0,799 & $-0,281$ & \\
\hline 2 & Comprehension & 0,662 & 0,469 & 0,584 & \\
\hline \multirow[t]{4}{*}{3} & Manageability & 0,988 & 0,151 & 0,027 & \\
\hline & $\begin{array}{l}\text { Average \% variance } \\
\text { accounted for }\end{array}$ & $56,53 \%$ & $29,44 \%$ & $14,02 \%$ & Total: $100 \%$ \\
\hline & Average $\%$ redundancy & $18,32 \%$ & $7,51 \%$ & $0,13 \%$ & Total: $27,23 \%$ \\
\hline & Canonical Correlations & 0,569 & 0,505 & 0,315 & \\
\hline
\end{tabular}


The independent variables accounted for only $21,98 \%$ of the variance of the $\mathrm{X}$-variate. The dependent variables, on the other hand, accounted for $56,53 \%$ of the variance of the Y-variate.

As far as redundancy is concerned, the independent variables accounted for $7,12 \%$ of the variance of the Y-variate, and the dependent variables accounted on average for $18,32 \%$ of the variance of the $\mathrm{X}$-variate.

On the surface, this looks like a contradiction. However, if canonical correlation analysis is compared with regression analysis, the results make good sense. The regression of $\mathrm{Y}$ on $\mathrm{X}$ is not the same as the regression of $\mathrm{X}$ on $\mathrm{Y}$. The canonical correlation represents the correlation of the X-composite with the Y-composite; given that the two composites have been formed by assigning weights to the X-components (independent variables) and the Y-components (dependent variables) so as to maximise the correlation between the two composites. The obtained canonical correlation is 0,569 and is statistically significant.

Applying stepwise regression analysis on the basis of the proposed model above yielded the following results for each dimension of Sense of Coherence (see Tables 7-9 below).

\section{Meaning}

Goal Commitment and Goal Conflict accounted for the most predictive variance of Meaning. In total these two dimensions accounted for $29 \%$ of the variance attributable to Meaning, as per the highlighted cell in Table 7 below.

\section{Manageability}

Dysfunctional Effects of Goals, Goal Clarity and Supervision Support/Participation, showed the greatest predictive ability of
Manageability. In total, these three dimensions account for $35 \%$ of the variance attributable to Manageability, as per Table 8 below.

\section{Comprehension}

Goal Specificity, and Goal Difficulty, showed the greatest predictive ability of Comprehension. In total, these two dimensions account for $18 \%$ of the variance attributable to Comprehension, as per Table 9 below.

\section{DISCUSSION}

Confirmatory reliability analysis of the dimensions in the questionnaires used, resulted in reliabilities ranging from 0,545 to 0,942 for the GSQ and 0,785 to 0,807 for the 29 item OLQ. A statistically significant canonical correlation was hypothesised between the Sense of Coherence dimensions of Antonovsky's (1987) 29 item OLQ (DV's) and the goal setting dimensions (IV's) as represented by the Locke and Latham (1984) GSQ. The canonical correlation of 0,569 obtained is statistically significant and hence the above hypothesis was supported implying that the use of principles embodied in goal setting can have an affect on an individuals' Sense of Coherence.

As aforementioned, this study has addressed a void in research with nothing to date to refer back to in literature. As a result, of particular interest to this research are those Sense of Coherence and goal setting dimensions contributing most to the canonical correlation. In terms of Sense of Coherence, all three dimensions contribute significantly to the canonical correlation. However, the Sense of Coherence dimension Manageability contributes by far the most $(0,988)$. In the context of how Antonovsky (1987) has operationalised Manageability, this dimension would seem

TABLE 7

DEPENDENT VARIABLE $=$ MEANING

\begin{tabular}{|c|c|c|c|c|c|c|c|c|c|}
\hline \multirow[t]{2}{*}{ Independent Variables } & \multirow[t]{2}{*}{$\mathrm{R}$} & \multirow[t]{2}{*}{$\mathbf{R}^{2}$} & \multirow[t]{2}{*}{ Adjusted $\mathrm{R}^{2}$} & \multirow[t]{2}{*}{$\begin{array}{c}\text { Std. Error } \\
\text { of Estimate }\end{array}$} & \multicolumn{2}{|c|}{$\begin{array}{l}\text { Unstandardised } \\
\text { Coefficients }\end{array}$} & \multirow{2}{*}{$\begin{array}{c}\begin{array}{c}\text { Standardised } \\
\text { Coefficients }\end{array} \\
\text { Beta }\end{array}$} & \multirow[t]{2}{*}{$\mathrm{t}$} & \multirow[t]{2}{*}{$P(F)$} \\
\hline & & & & & B & Std. Error & & & \\
\hline Goal Conflict & 0,470 & 0,221 & 0,211 & 0,729 & 0,348 & 0,080 & 0,416 & 4,334 & 0,000 \\
\hline Goal Commitment & 0,554 & 0,307 & 0,289 & 0,693 & 0,349 & 0,112 & 0,298 & 3,107 & 0,003 \\
\hline
\end{tabular}

TABLE 8

DEPENDENT VARIABLE $=$ MANAGEABILITY

\begin{tabular}{|c|c|c|c|c|c|c|c|c|c|}
\hline \multirow[t]{2}{*}{ Independent Variables } & \multirow[t]{2}{*}{$\mathbf{R}$} & \multirow[t]{2}{*}{$\mathbf{R}^{2}$} & \multirow[t]{2}{*}{ Adjusted $\mathrm{R}^{2}$} & \multirow[t]{2}{*}{$\begin{array}{l}\text { Std. Error } \\
\text { of Estimate }\end{array}$} & \multicolumn{2}{|c|}{$\begin{array}{l}\text { Unstandardised } \\
\text { Coefficients }\end{array}$} & \multirow{2}{*}{$\begin{array}{c}\begin{array}{c}\text { Standardised } \\
\text { Coefficients }\end{array} \\
\text { Beta }\end{array}$} & \multirow[t]{2}{*}{$t$} & \multirow[t]{2}{*}{$P(F)$} \\
\hline & & & & & B & Std. Error & & & \\
\hline $\begin{array}{l}\text { Dysfunctional Effects } \\
\text { of Goals }\end{array}$ & 0,520 & 0,270 & 0,261 & 0,73173 & 0,511 & 0,124 & 0,575 & 4,109 & 0,000 \\
\hline Goal Clarity & 0,576 & 0,332 & 0,315 & 0,70460 & 0,372 & 0,120 & 0,335 & 3,102 & 0,003 \\
\hline $\begin{array}{l}\text { Supervision Support/ } \\
\text { Participation }\end{array}$ & 0,613 & 0,376 & 0,351 & 0,68560 & $-0,241$ & 0,104 & $-0,315$ & $-2,320$ & 0,023 \\
\hline
\end{tabular}

TABLE 9

DEPENDENT VARIABLE $=$ COMPREHENSION

\begin{tabular}{|c|c|c|c|c|c|c|c|c|c|}
\hline \multirow[t]{2}{*}{ Independent Variables } & \multirow[t]{2}{*}{$\mathbf{R}$} & \multirow[t]{2}{*}{$\mathbf{R}^{2}$} & \multirow[t]{2}{*}{ Adjusted $\mathrm{R}^{2}$} & \multirow[t]{2}{*}{$\begin{array}{l}\text { Std. Error } \\
\text { of Estimate }\end{array}$} & \multicolumn{2}{|c|}{$\begin{array}{l}\text { Unstandardised } \\
\text { Coefficients }\end{array}$} & \multirow{2}{*}{$\begin{array}{c}\begin{array}{c}\text { Standardised } \\
\text { Coefficients }\end{array} \\
\text { Beta }\end{array}$} & \multirow[t]{2}{*}{$\mathrm{t}$} & \multirow[t]{2}{*}{$P(F)$} \\
\hline & & & & & B & Std. Error & & & \\
\hline Goal Specificity & 0,386 & 0,149 & 0,138 & 0,62496 & 0,414 & 0,095 & 0,464 & 4,332 & 0,000 \\
\hline Goal Difficulty & 0,448 & 0,200 & 0,180 & 0,60957 & $-0,250$ & 0,111 & $-0,240$ & $-2,245$ & 0,028 \\
\hline
\end{tabular}


the most malleable to influence, being the belief in resources not only internal but external including a supervisor, colleague or institution. In terms of goal setting, the dimensions: Goal Setting in Performance Appraisal, Organisational Facilitation of Goal Achievement, Dysfunctional Effects of Goals and Goal Clarity contribute most to the correlation.

The above highlighted goal setting dimensions would seem to support the notion of Manageability contributing most to the canonical correlation, bar Dysfunctional Effects of Goals, in that where goals set in the organisation are seen from a negative perspective, this should surely not promote a greater sense of an ability to deal with challenges. Perhaps an answer to the anomaly may lie in the fact that individuals with a strong sense of Manageability in their lives, believe they are able to handle life's challenges through a variety of GRR's. This is then evidenced by higher Manageability scores in the face of Dysfunctional Goals which may even cause 'proof' of Manageability to surface. This implies that Dysfunctional Goals may in part be related to the less malleable component of Manageability, that is formed through life's experiences.

Turning towards the stepwise regression analysis, individual predictive ability of the goal setting dimensions on the Sense of Coherence dimensions are discussed.

Of all the factors which showed predictive ability of Meaning, the best predictors were Goal Conflict and Goal Commitment. Goal Commitment seems more logically to predict meaning in that the motivation to achieve goals and being involved in setting goals, would imply that the individual is able to create a sense of Meaning through this process. It is interesting to note the positive predictive ability of an individual being motivated by the goal on Meaning is significant. This emphasises the importance of setting goals that are relevant for the individual, allowing them to be involved in the process and allowing the individual to align the goal with some form of intrinsic motivation. However a caveat, as based on the discussed low reliability of this goal setting dimension, is that its predictive ability as a construct within this questionnaire, may be limited.

Goal Conflict, however, is more perplexing. It is proposed that Goal Conflict may cause evidence of Meaning in individuals with a strong Sense of Coherence, to surface. Possibly these individuals are more readily able to recognise incongruence in terms of actions which conflict with their goals. Hence the person with a lower sense of Meaning may not experience conflict to the same degree as the sense of Meaning they ascribe their work goals may be less defined.

Off all the factors which showed predictive ability of Manageability, the strongest were Dysfunctional Effects of Goals, Supervision Support/Participation and Goal Clarity. The latter two stand to reason in that Supervision Support will offer the individual a further means to be able to deal with challenges goals may represent, whilst Goal Clarity will assist the individual in being able to interpret exactly what is required and hence enable the individual to identify and mobilise the necessary resources.

As with the canonical correlation discussion above the anomaly of Dysfunctional Effects of Goals being associated with Manageability may be the challenge this represents for the individual with a high Sense of Coherence, causing evidence of Manageability to surface.

The Goal Setting dimensions that contributed the most variance to predicting Comprehensibility were Goal Specificity and Goal Difficulty. Conversely Goal Clarity did not account for as much predictive variance as did Goal Specificity and perhaps this is due in part to the fact that the questions which make up Goal Clarity relate more to how the individual interprets the clarity of a goal given to them i.e. "I understand what I am supposed to do on my job"; I have specific clear goals to aim for on my job", hence this appears to be clothed in the passive acceptance of an instruction. Goal Specificity, however, includes more of an active approach required by the individual in that questions relate to: "I am always able to break my goals down in specific measures"; "I always write my project goals down" and "My goals definitely have identifiable components". Hence the individual with a higher sense of Comprehensibility may be more prone to take an active role in clarifying the task at hand, which would aid Comprehensibility thereof.

Goal Difficulty contributing to Comprehensibility seems a further anomaly. Perhaps reasons for this may exist in goal setting research, in that the two most valid predictors of increased performance in terms of goal setting dimensions are Goal Specificity and Goal Difficulty (Kalnbach \& Hinsz, 1999). This may imply that when an individual with a higher Sense of Coherence is faced with challenging goals that require "all their efforts and persistence to achieve", they employ strategies of breaking the goal down into identifiable components and creating 'sense' of the challenge. In other words, these individuals may engage in an active role to create an understanding of the task at hand, or improve their Comprehensibility of the situation.

An interesting note on Comprehensibility as a dimension of Sense of Coherence is that it appears the least susceptible to moderating effects of goal setting in that goal setting dimensions only accounted for $18 \%$ variance of Comprehensibility. It is suggested that Comprehensibility may be the least malleable of all the Sense of Coherence dimensions (in terms of organisational or other external influence) and may be more linked to innate characteristics such as aptitude or emotional intelligence (having an ability to stand back from a challenge to gain a broader perspective, over being mired in the detail of the challenge and unable to see a broader picture) (Goleman, 1995). In support of this, both goal setting dimensions that contributed most to Comprehensibility seem to demand an active role on behalf of the individual. Other efforts (such as supervision support or providing clarity on the goal) of the organisation seem less likely to account for the creation of Comprehensibility for an individual.

\section{Conclusion}

Stress is a pervasive and formidable foe in the workplace today, having latent but potentially devastating affects on our immunity systems, resulting in susceptibility to life threatening diseases (Kiecolt-Glaser et al., 2002; NIOSH, 2002). Sense of Coherence as a construct has been well validated in terms of equipping an individual to be more resilient to stress and hence avoid the ill effects stress may result in (Strümpfer \& Wissing, 1998). It has been the aim of this research to assess the moderating effects of a widely used, organisationally and academically accepted motivational technique, namely, goal setting, on Sense of Coherence (Kalnbach \& Hinsz, 1999). The premise of the research being, that if goal setting is able to influence Sense of Coherence, organisations could employ related dimensions of goal setting, to enhance an environment which may promote Sense of Coherence in the workplace and better equip individuals to handle stress.

Based on the GSQ of Locke and Latham (1984) and the 29 item OLQ of Antonovsky (1987), the results of the research were encouraging in that dimensions of goal setting did account for predictive variance in terms of dimensions of Sense of Coherence. This was supported by a statistically significant 
canonical correlation of 0,569 between dimensions of the goal GSQ and the 29 item OLQ. The significant contribution of Manageability to the canonical correlation $(0,988)$ and the resulting goal setting factors that contribute the most variance to this Sense of Coherence dimension presents interesting findings. Managers and supervisors can influence the perception of an individual in believing they can handle a challenge based on support and participation. They can also add to the meaning the individual has in what they are doing by involving them in the goal setting process and to a lesser degree, make the goal specific to enhance comprehensibility for the individual.

On a final note, it is interesting to note that although Sense of Coherence is considered a relatively enduring orientation, one that is formed through many life experiences and mostly will mature by about 30 years of age (Antonovsky, 1987), Antonovsky does assert that various situations or contexts can influence an individual's Sense of Coherence. This study does not include a longitudinal component, however, the results have provided evidence that there is a positive relationship between dimensions of Sense of Coherence and goal setting, implying the potential opportunity for management in the workplace to initiate actions which will contribute to an individual's Sense of Coherence.

\section{Recommendations}

As with many such exploratory studies in the workplace, an improved sample size may have enhanced the predictive ability of the Goal Setting dimensions on Sense of Coherence. However, perhaps a more pertinent recommendation for future research is to consider using an experimental design which would allow for some form of intervention and control group, in order to test whether or not the dimensions proposed above do have an effect on dimensions of Sense of Coherence. It is recommended that within the same or similar context (i.e. work within a project environment), the experimenter test the Sense of Coherence of a randomly selected group of individuals soon after commencement of the project. Of that group, allow certain individuals to be involved in setting specific and challenging goals (Goal Specificity, Goal Difficulty and Goal Commitment) and then provide Supervision Support and Participation. After an elapse of time (not more than 6 months), both groups control and experimental group should be retested for any possible affect on Sense of Coherence.

The advantage of the above recommendation would in addition to the obvious advantage of a $2 \times 2$ factorial experimental design, be that the theory of goal setting would be tested in practice and in addition, the effect of goal setting would be able to be tested over time. This would give insight into the longitudinal affect of goal setting on Sense of Coherence.

A second recommendation is to consider a new goal setting questionnaire. Or alternatively, reassess the empirical properties of the Goal Setting Questionnaire developed by Locke and Latham (1984). The authors are aware of no other study to validate the questionnaire and although the study performed by Lee et al. (1991) does provide some interesting insights, further development of such a questionnaire would seem warranted based on the usefulness of such an instrument. In conjunction with such an instrument, the experimenter would be able to assess for other factors, which may have an influence on Sense of Coherence or dimensions thereof. Such a study could attempt to explore the unaccounted for predictive variance in this study, as well as investigate if the findings would be replicated in another similar environment. This would be particular useful in consideration of the apparent lack of susceptibility to influence, Comprehension displayed in terms of Goal Setting dimensions, within this research.

\section{REFERENCES}

Adams, T. B., Bezner, J. R., Drabbs, M. E., Zambarano, R. J. \& Steinhardt, M. A. (2000). Conceptualization and measurement of the spiritual and psychological dimensions of wellness in a college population. Journal of American College of Health, 48, 165-182.

Antonovsky, A. (1979). Health, stress and coping. San Francisco: Jossey-Bass.

Antonovsky, A. (1987). Unravelling the mystery of health: How people manage stress and stay well. San Francisco: Jossey-Bass.

Antonovsky, A. (1994). The sense of coherence: An historical and future perspective. In H. I. McCubbin, E. A. Thompson, A. I. Thompson \& J. E. Fromer (Eds.), Sense of coherence and resiliency (pp.3-20). Madison, WI: University of Wisconsin System.

Bandura, A. (1977). Self-efficacy: Toward a unifying theory of behavioural change. Psychological Review, 84, 191-215.

Carmel, S. \& Bernstein, J. (1989). Trait anxiety and sense of coherence: A longitudinal study. Psychological Reports, 65, 221-222.

Carolyn, A. (2001). Reports link work stress, absence. Business Insurance, 35, 17-19.

Cascio, W. F. (1989). Managing human resources. New York: McGraw-Hill International Editions.

Flannery, R. B. \& Flannery, G. J. (1990). Sense of coherence, life stress and psychological distress: A prospective methodological enquiry. Journal of Clinical Psychology, 46, 415-418.

Goleman, D. (1995). Emotional intelligence: Why it can matter more than IQ. Great Britain: Bloomsbury Publishing.

Hart, K. E., Hittner, J. B. \& Paras, K. C. (1991). Sense of coherence, trait anxiety and the perceived availability of social support. Journal of Research in Personality, 25, 137-145

Hinsz, V. B. (1995). Goal setting by groups performing an additive task: A comparison with individual goal setting. Journal of Applied Social Psychology, 1995, 25, 965-990.

Hobson, C. J., Delunas, L. \& Kesic, D. (2001). Compelling evidence of the need for corporate work/life balance initiatives: results form a national survey of stressful events. Journal of Employment Counselling, 38, 38-45.

Hollenbeck, J. R. \& Klein, H. J. (1987). Goal commitment and the goal-setting process: problems, prospects, and proposals for the future research. Journal of Applied Psychology, 70, 492-504.

Kalnbach, L.R. \& Hinsz, V. B. (1999). A conceptualization and the test of the influences of the individual differences in goal setting situations. Journal of Applied Social Psychology, 29, 1854-1878.

Kiecolt-Glaser, J.K., McGuire, L., Robles, T.F., \& Glaser, R. (2001). Psychoneuroimmunology and psychosomatic medicine: Back to the future. Psychosomatic Medicine, 63, 1-14.

Kiecolt-Glaser, J.K., McGuire, L., Robles, T.F., \& Glaser, R. (2002). Emotions, morbidity, and mortality: New perspectives from Psychoneuroimmunology. Annual Review of Psychology, 53, 83-107.

Kivimaki, M., Kalimo, R. \& Toppinen, S. (1998). Sense of coherence as a modifier of occupational stress exposure, stress perception and experienced strain: A study of industrial managers. Psychological Reports, 83, 971-981.

Kobasa, S .C. (1979). Stressful life events, personality, and health: An inquiry into hardiness. Journal of Personality and Social Psychology, 37, 1-11.

Lee, C., Bobko, P., Early, P.C. \& Locke, E.A. (1991). An empirical analysis of a goal setting questionnaire. Journal of Organizational Behavior, 12, 467-482.

Locke, E. A. \& Latham, G.P. (1984). Goal setting: A motivational technique that works. New Jersey: Prentice-Hall.

Locke, E. A., Shaw, K. N., Saari, L. M. \& Latham, G. P. (1981). Goal setting and task performance: 1969-1980. Psychological Bulletin, 90, 125-152. 
McSherry, W. C. \& Holm, J. E. (1994). Sense of coherence: Its effects on psychological and physiological processes prior to, during and after a stressful situation. Journal of Clinical Psychology, 50, 476-486.

NIOSH (National Institute for Occupational Safety and Health) (1999). Stress at work. Retrieved from the World Wide Web at http://www.cdc.gov/niosh/stresswk.html on the 10.07.2002.

Sauter, S., Murphy, L., Colligan, M., Swanson, N., Hurrell, J., Scharf, J., Sinclair, R., Grubb, P., Goldenhar, L., Alterman, T., Johnston, J., Hamilton, A. \& Tisdale, J. (2002), Stress at Work. DHHS (NIOSH) Publication No. 99-101.

Scheier, M. F. \& Carver, C. S. (1987). Dispositional optimism and physical well being: The influence of generalized outcome expectancies on health. Journal of Personality, 55, 169-210.

Shaughnessy, J.J. \& Zechmeister, E.B. (1997). Research methods in psychology (4th ed.). New York: McGraw-Hill.
Strümpfer, D.J.W. \& Wissing, M.P. (1998). Review of South African data on the Sense of Coherence Scale as a measure of fortigenesis and salutogenesis. Paper presented at annual Congress of the Psychological Society of South Africa, Cape Town, South Africa. Strümpfer, D.J.W. (1990). Salutogenesis: A new paradigm. South African Journal of Psychology, 20, 45-52.

Strümpfer, D.J.W. (1986). Executive Stress. In Barling, J. Fullgar, C. \& Bluen, S. (Eds.) Behaviour in organisations: South African perspectives.

Sullivan, C.A. (1995). A salutogenic study of stress. Unpublished masters thesis. Johannesburg, Rand Afrikaans University.

Terborg, J. R. (1976). The motivational components of goal setting. Journal of Applied Psychology, 61, 613-621.

Tubbs, M. E. (1986). Goal setting: a meta-analytic examination of the empirical evidence. Journal of Applied Psychology, 71, 471-483.

Worrall, L. \& Cooper, C.L. (1995). Executive stress in different industrial sectors, structures and sizes of business. Personnel Review, 24, 3-12. 